Pouring its turgid sperm into the Shannon. Ah 'tis, he says, Ah yes, a true bloody fact, And turns to talk about the Charolais and the Whitehead Herefords With Jerry McDermot up the bar.

No JJ, listen to me, I tell him, Look again, look here:

This is the manhood of Ireland plunging

Into that great slut of an ocean.

'Tis that, he says, Yes indeed, I see it there,

And calls for another pint from Clare Egan for each of us

And helps himself to a Woodbine out of Jerry's pack.

Mary Carey comes over,

Dangling a half-glass between two fingers.

And what was this you were mentioning over here JJ, she says.

Mary Mary, let me explain, I say,

We were discussing the virtue of the Whitehead cattle

As compared to the Charolais ...

Which are a dead loss, says Jerry McDermot.

Oh I see, she says, Oh yes.

Nothing of the kind, Clare tells her,

The infamous Yank is lying to you, Mary:

$\mathrm{He}$ and JJ were examining the River Shannon on this map

And how it pours itself into the ocean

In an act of fornication.

Ah go on, says Mary Carey.

A dead loss, says Jerry McDermot.

\title{
Litany Against the Bellyache, Upon St. Brigid's Day
}

Then it was the fierce place in my middle

where the crazed flatus was

\& with it a prayer to holy Mother Brigid

that she might heal me from her nunnery in the sky

because I suffered nightsweats $\&$ burnings at stool

because it was the tea-colored diarrhea

because I was in pain

because there was neither joy in my supper nor bliss in my bedding 
because it was Venice all night in my mind

because we two sat watching the vaporetti

because she had hastened to join me after my drunken entreaties

because the vaporetti came back $\&$ forth

because none of this was true

because there had been neither entreaty nor hastening

I was too much alone

I was in pain because of my flatus

I was lying awake in the midnight over too much flatus

I spent my last prayer like a hasty letter home

I brought her down to me in a glint of ice-light

where the dour crows perched in the branches

where their broken cries came raggedly down from above

where the Saint looked over the windowsills of joy

where she had come to me anyway true or untrue

where I had told her over again the same brave lunacies

where the blight in my belly sang "Stranger in Paradise"

instead of Benedictus

instead of any Sunday by the Grand Canal

nor any vaporetti

but the Rue Saint André-des-Arts in Montparnasse

or the alleys of Iraklion black with crones

or the gray isles west of Inishmore

where never womenfolk ever were nor any thought of them 